\title{
Relevant problems in collaborative processes of non-hierarchical manufacturing networks
}

\author{
Beatriz Andrés, Raul Poler \\ Research Centre in Production Management and Engenieering (CIGIP) (Spain) \\ beaanna@,cigip.upv.es, rpoler@,cigip.upv.es
}

Received: September 2012

Accepted: March 2013

\section{A bstract:}

Purpose The purpose of this paper is to identify some of existing problems associated with collaboration among SMEs of the same network. Concretely, the problems are focused. The research objective is to identify the most relevant problems existing when SMEs have to deal with decentralized decisions (DDM).

Design/mathodalogy/approadr. Through the literature review there have been collected collaborative problems caused by inter-organizational barriers. The approach taken is a qualitative study and analysis that classifies collaborative problems from less important to very important. In light of this, we are able to identify what are the most relevant problems to study in the NHN collaborative context.

Findings: The developed methodology allows researchers to indentify amongst the collaborative problems those that are most relevant to solve in the NHN context, with the main aim of providing solutions in the future. The research aim is to provide the expert in the collaborative field a starting point to address the collaborative problems SMEs can find when belonging to collaborative networks.

Research limitations/implications: Not all the problems that appear when an SME establish collaborative relationships, in a NHN, are considered. The identified problems have been arisen because there are discussed in the literature for addressing collaborative problems among 
networked partners. Identified problems are also considered because there are relevant to achieve collaboration among SMEs.

Originality/value The degree of coverage and the degree of significance is the taxonomy criteria used to identify the importance of solution degree of the encountered collaborative problems, in NHN context, in order to provide a future research of solutions to overcome them.

Keywards: collaborative problems, non-hierarchical networks, decentralised decisions

\section{Introduction}

In today's global market, small and medium enterprises (SMEs) competitiveness and growth rely largely on the movement towards highly innovative industrial systems and agile networked enterprises through the creation and consolidation of non-hierarchical manufacturing networks (NHN) of multinational SMEs.

Traditional hierarchical manufacturing networks (HN) are based on centralized decision models (CDM), where the majority of the involved companies have to adapt themselves to the constraints defined by a minority of dominant firms. CDM generates significant inefficiencies for the entire network due to the underestimation of the constraints of each company. The HN performance can be improved through considering decentralized decision-making models (DDM), thus create NHN. The main contribution offered by DDM in NHN is that all the networked partners are involved in the business processes management in a collaborative way. DDM improves each network node commitment as regards to the overall goal of the network while improving communication, collaboration and flows among nodes (Poler, 2010). In short, NHN equally considers all network partners.

An increasing number of organization forms in collaborative networks are emerging as a result of the in information and communication technologies advances, the market and society needs and the international projects progress. Andrés and Poler (2011) identify and analyze problems that arise in collaborative networks and propose a classification matrix for the most relevant ones.

This paper proposes a methodology for selecting amongst all the collaborative problems, identified in Andrés and Poler (2011), those considered more relevant to support collaborative process in NHN. The problems identification will allow us to find solutions in future research. The paper is organised as follows. In next section, the identified problems when collaborative relationships are established in NHN are provided. Then, previous methodology to identify the most relevant problems to be solved in the collaborative and decentralised networks is developed. Finally, the further research and conclusions are given. 


\section{Identified Problems in Collaborative Networks}

In collaborative networks context there is a wealth of knowledge available, but there is a need to consolidate this knowledge through developing a framework that provides models, guidelines and tools for supporting collaborative processes. Despite the interest in the topic under research, there is no framework that relates problems and solutions associated with collaborative processes in NHN. Andrés and Poler (2011) review some of the existing problems affecting the network collaborative processes and propose a collection of solutions that address the most relevant problems that affect collaborative processes caused by the interorganizational barriers (Poler, Ortiz, Tormo, \& Gutierrez, 2002). Furthermore, the degree of coverage analysis is proposed for identifying the extent to which the literature provided solutions, of the identified problems, can be adopted to address the problems in NHN context. In this way, if the solution is specifically provided for NHN it has an excellent degree of coverage for NHN (O). Otherwise, if the solution is focused for $\mathrm{HN}$ it must be determined in which extent the provided solution can be implemented in NHN. For that, the solution is classified in a poor, unsatisfactory, acceptable or satisfactory degree of coverage (Andrés and Poler, 2011).

The poor coverage level $(O)$ is associated with those solutions that cannot be applied to NHN. The problem is listed as an unsatisfactory coverage level (๑) when the solution concept or idea can be implemented in NHN but the solution itself cannot be applied due to the solution is subject to a HN features. The degree of acceptable coverage ( $)$ is associated with problems whose solutions are outlined for the HN scenarios but there can be applied to NHN. The satisfactory coverage level ( $)$ is allocated to those problems for which the majority solution lines are adaptable or defined for NHN.

The identified problems are conceptually arranged according to (i) the decision-making level: strategic, tactical and operational (S/T/O) and (ii) to the used criteria for the solutions classification: models, guidelines and tools $(M / G / T)$.

The classification scheme of the identified problems affecting collaboration in manufacturing networks is showed in Table 1, from both HN and NHN perspective.

The identified problems have been discussed in the literature for addressing collaborative problems among networked partners. Furthermore, the problems are considered due to there are important and complex to achieve collaborative processes among networked SMEs. 


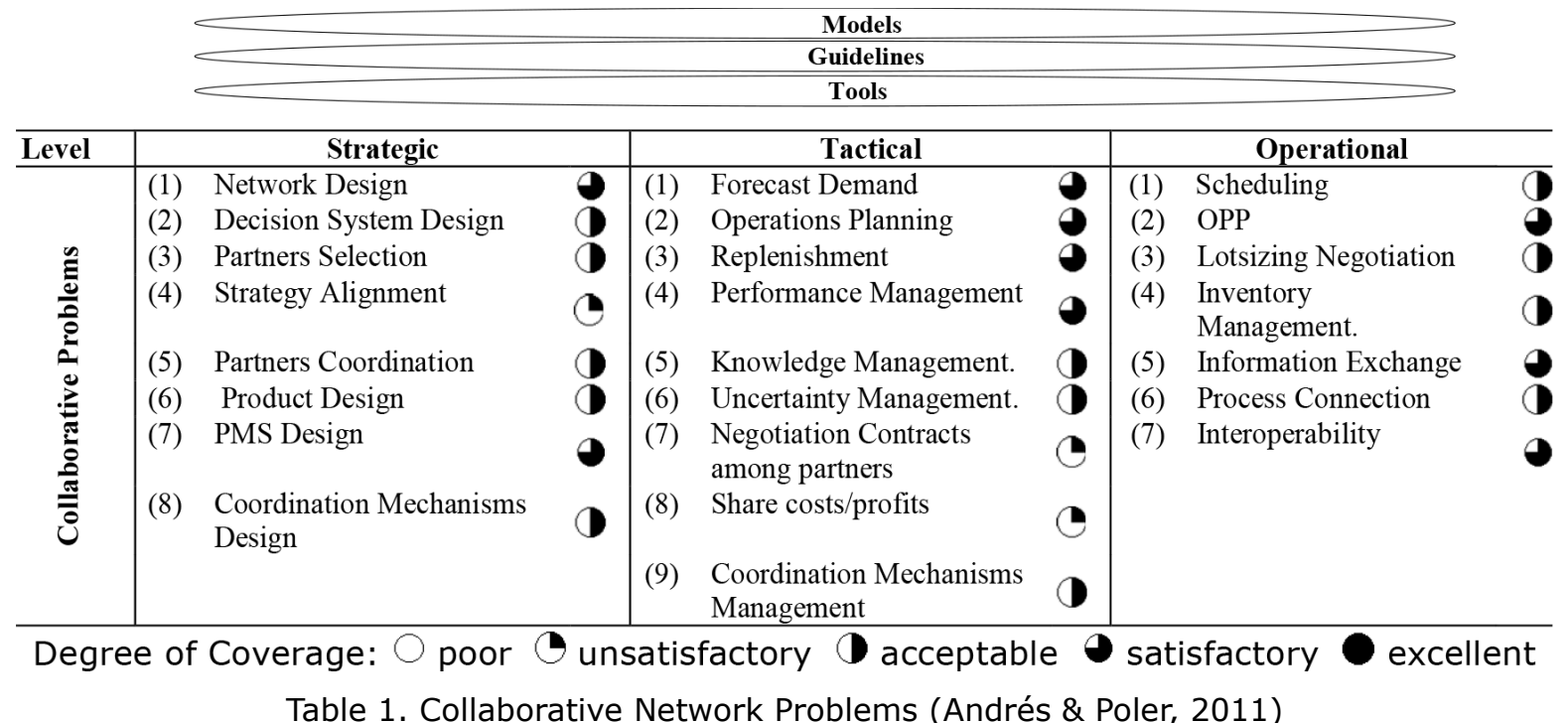

\section{Selection of relevant problems for NHN context}

According to the proposed matrix and the degree of coverage (Table 1), problems with unsatisfactory solutions in NHN context have been identified. The aim of this section is to identify amongst all the identified problems, those that have less satisfactory solutions and are considered more important for providing solutions in NHN context. The methodology for selecting the most relevant problems in NHN context is proposed next (Figure 1).

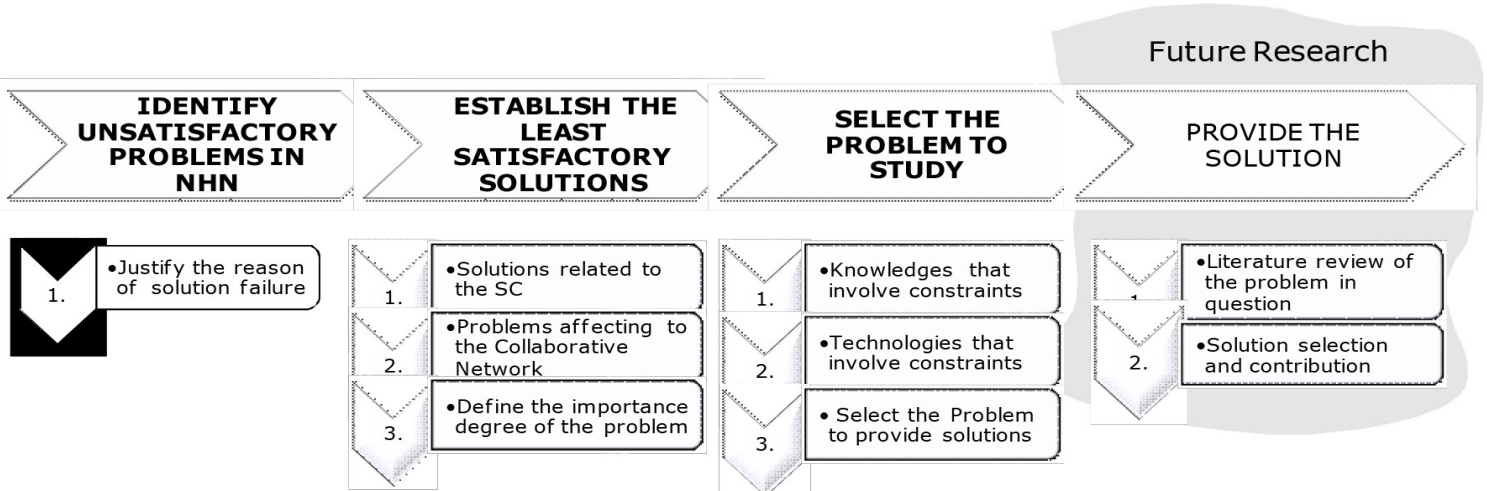

Figure 1. Methodology for selecting relevant problems in NHN

Following the methodology the first step is the justification of the solution failure that will prove why the problem is considered totally or partially unresolved taking into account the degree of coverage results.

Amongst the unresolved and partially resolved problems, we proceed to define the degree of coverage of the problem (Table 2). Each problem is associated with a certain degree of coverage. 


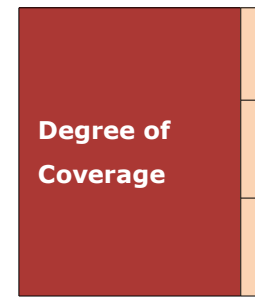

Problem with non satisfactory degree of coverage. Is necessary to cover it. The solutions do not cover the problem in NHN context

Problem with an acceptable degree of coverage. Is necessary to cover it. The provided solutions have a half degree of coverage in NHN context

Problem with a satisfactory degree of coverage. The problem is completely covered in NHN context by the solutions proposed in the literature

Table 2. Degree of Coverage of the problem

Once identified the degree of coverage of the problem, the third phase is to determine which are the most important problems when decentralized decision making and collaborative nonhierarchical relationships are established in a network (Table 3).

\begin{tabular}{|c|c|c|}
\hline \multirow{3}{*}{$\begin{array}{l}\text { Degree of } \\
\text { significance } \\
\text { to establish } \\
\text { collaborative } \\
\text { relations }\end{array}$} & $\begin{array}{l}\text { Problem with a high significant degree to establish } \\
\text { collaborative relationships in a NHN }\end{array}$ & $\begin{array}{l}\uparrow \uparrow \\
\uparrow\end{array}$ \\
\hline & $\begin{array}{l}\text { Problem with significant degree to establish } \\
\text { collaborative relationships in a NHN }\end{array}$ & $\uparrow \uparrow$ \\
\hline & $\begin{array}{l}\text { Problem with a lower degree of importance to } \\
\text { establish collaborative relationships in a NHN }\end{array}$ & $\uparrow$ \\
\hline
\end{tabular}

Table 3. Degree of significance for establishing collaborative relationships among NHN collaborative members

The classification of the problems regarding (i) the degree of coverage of the solution and (ii) the degree of significance to establish decentralized and collaborative relationships enables the definition of the degree of importance for providing a solution (Table 4), from highest to lowest importance areas (Figure 2).

\begin{tabular}{|c|c|l|}
\hline $\begin{array}{c}\text { Degree of } \\
\text { Coverage }\end{array}$ & $\begin{array}{c}\text { Degree of significance for } \\
\text { establishing collaborative } \\
\text { relations }\end{array}$ & \multicolumn{1}{|c|}{$\begin{array}{c}\text { Degree of Importance } \\
\text { for providing a solution for } \\
\text { NHN }\end{array}$} \\
\hline \begin{tabular}{c|c}
$\uparrow \uparrow \uparrow$ \\
$\uparrow \uparrow$ or $\uparrow$
\end{tabular} & $\begin{array}{l}\text { Very important } \\
\text { Important }\end{array}$ \\
\hline & $\begin{array}{c}\uparrow \uparrow \uparrow \\
\uparrow \uparrow\end{array}$ & $\begin{array}{l}\text { Very important } \\
\text { Important } \\
\text { Less important }\end{array}$ \\
\hline & $\begin{array}{c}\uparrow \uparrow \uparrow \\
\text { or } \uparrow \uparrow\end{array}$ & $\begin{array}{l}\text { Important } \\
\text { Less important }\end{array}$ \\
\hline
\end{tabular}

Table 4. Allocation rule for determining the degree of importance in the problem resolution

The degree of importance for providing a solution in the NHN context determines the problems in which the proposal solution should focus on (table 5). According to table 3, the relevant problems to provide solutions correspond with those classified with less acceptable degrees of coverage $(\circlearrowleft / \oplus)$ and are pretty significant for establishing non-hierarchical collaborative relationships ( $\uparrow \uparrow \uparrow / \uparrow \uparrow)$. In this way, the most significant problems for establishing nonhierarchical collaborative relationships will be classified as "very important", while less influential problems for establishing collaborative relationships will be classified as "important" or "less important" (Figure 3). 


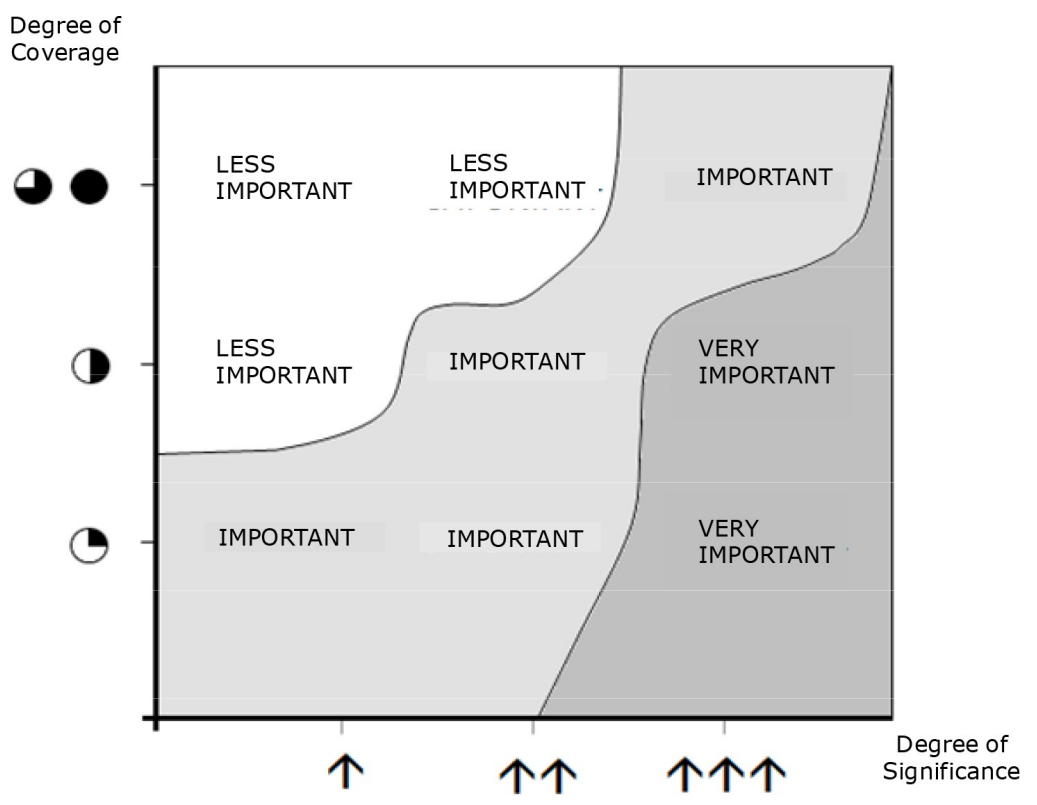

Figure 2. Areas of importance solution degree

\begin{tabular}{|c|c|c|c|c|}
\hline & Candidate problems & Coverage & Significance & Solution/Importance degree \\
\hline 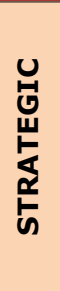 & $\begin{array}{l}\text { Network Design } \\
\text { Decision System Design } \\
\text { Partners Selection } \\
\text { Strategy Alignement } \\
\text { Partners Coordination } \\
\text { Product Design } \\
\text { PMS Design } \\
\text { Coordination Mechanisms Design }\end{array}$ & & $\begin{aligned} \uparrow & \uparrow \uparrow \\
\uparrow & \uparrow \uparrow \\
& \uparrow \uparrow \\
\uparrow & \uparrow \\
\uparrow & \uparrow \\
\uparrow & \uparrow \uparrow \\
& \uparrow \\
\uparrow & \uparrow \\
\uparrow & \uparrow \\
\uparrow & \uparrow\end{aligned}$ & $\begin{array}{l}\text { Less important } \\
\text { Very important } \\
\text { Important } \\
\text { Very important } \\
\text { Very important } \\
\text { Important } \\
\text { Less important } \\
\text { Very important }\end{array}$ \\
\hline 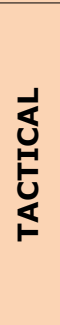 & $\begin{array}{l}\text { Forecast Demand } \\
\text { Operations Planning } \\
\text { Replenishment } \\
\text { Performance Management } \\
\text { Knowledge Management } \\
\text { Uncertainty Management } \\
\text { Contracts } \\
\text { Share Costs/Benefits } \\
\text { Coordination Mechanisms Management }\end{array}$ & & $\begin{aligned} & \uparrow \uparrow \\
& \uparrow \uparrow \\
& \uparrow \uparrow \\
& \uparrow \\
& \uparrow \\
\uparrow & \uparrow \uparrow \\
& \uparrow \uparrow \\
\uparrow & \uparrow \uparrow \\
& \uparrow \uparrow \\
& \uparrow \uparrow \\
\uparrow & \uparrow \uparrow\end{aligned}$ & $\begin{array}{l}\text { Less important } \\
\text { Less important } \\
\text { Less important } \\
\text { Less important } \\
\text { Very important } \\
\text { Important } \\
\text { Very important } \\
\text { Very important } \\
\text { Very important }\end{array}$ \\
\hline 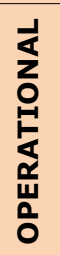 & $\begin{array}{l}\text { Scheduling } \\
\text { Order Promising Process } \\
\text { Lot Sizing Negotiations } \\
\text { Inventory Management } \\
\text { Information Exchange } \\
\text { Processes Connection } \\
\text { Interoperability }\end{array}$ & $\underset{0}{0}$ & $\begin{aligned} & \uparrow \\
\uparrow & \uparrow \\
\uparrow & \uparrow \\
\uparrow & \uparrow \\
\uparrow & \uparrow \\
\uparrow & \uparrow \\
\uparrow & \uparrow\end{aligned}$ & $\begin{array}{l}\text { Less Important } \\
\text { Less Important } \\
\text { Less Important } \\
\text { Important } \\
\text { Less Important } \\
\text { Important } \\
\text { Less Important }\end{array}$ \\
\hline
\end{tabular}

Table 5. Problems classification according the degree of coverage and the degree of significance

Before selecting the problem to provide a solution we have to ensure that the selected problem has not been previously addressed from the NHN perspective. Therefore, a literature review must be specifically carried out for papers dealing with the selected problem. Updating the literature review for a particular problem will allow us to decide if the selected problem does really need future research to propose a solution.

Finally, the required previous knowledge and technological limitations must be taken into account for selecting the problem under study and provide a subsequent solution. 


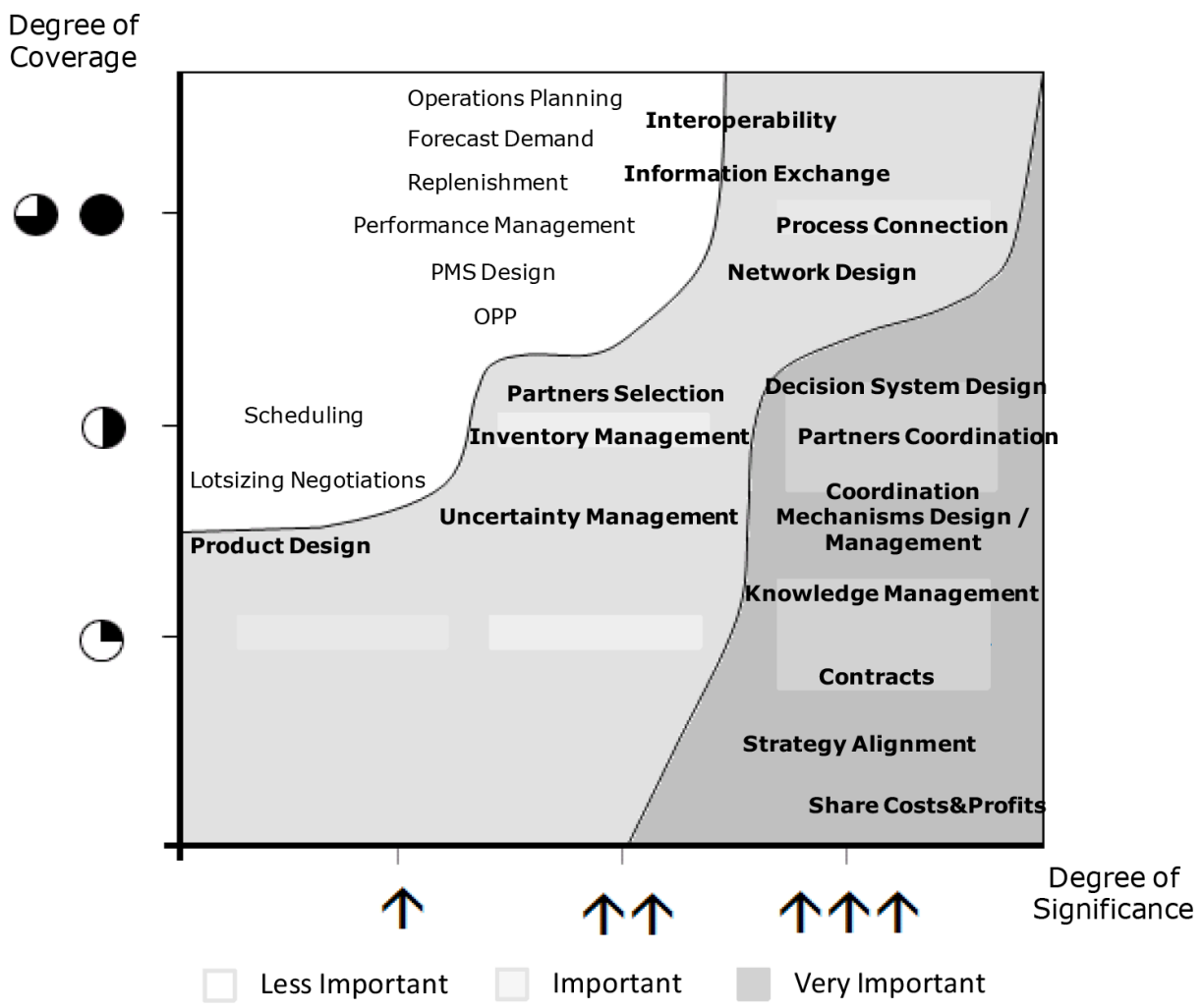

Figure 3. Relevant Problems to provide solutions

\section{Further Research}

Once the problems that need further research are detected, the building blocks of the collaborative framework for non-hierarchical manufacturing networks are identified. Figure 4 shows the building blocks that need further research. Less shaded blocks correspond with the problems that have been already solved in the literature, in a particular solution area (models, guidelines and tools), with a satisfactory or excellent degree of coverage. Blocks with intense shading correspond to the problems whose provided solutions, in the literature, have an unsatisfactory degree of coverage. Problems with intense shading have greater need to provide a solution in the NHN context. Finally, blocks with intermediate shading correspond to those solutions that solve the problem in an acceptable degree of coverage or in a centralized context; thus the problem requires being adapted to the decentralized context. Whether the problem is not covered but is not required to be covered in a determinate area due to there are other solution areas that address it satisfactorily, is also classified with intermediate shading.

Future research lines are focused on building a Collaborative Framework for Non-Hierarchical Manufacturing Networks that will focus on problems which current solutions do not provide satisfactory degrees of coverage in the NHN perspective. 


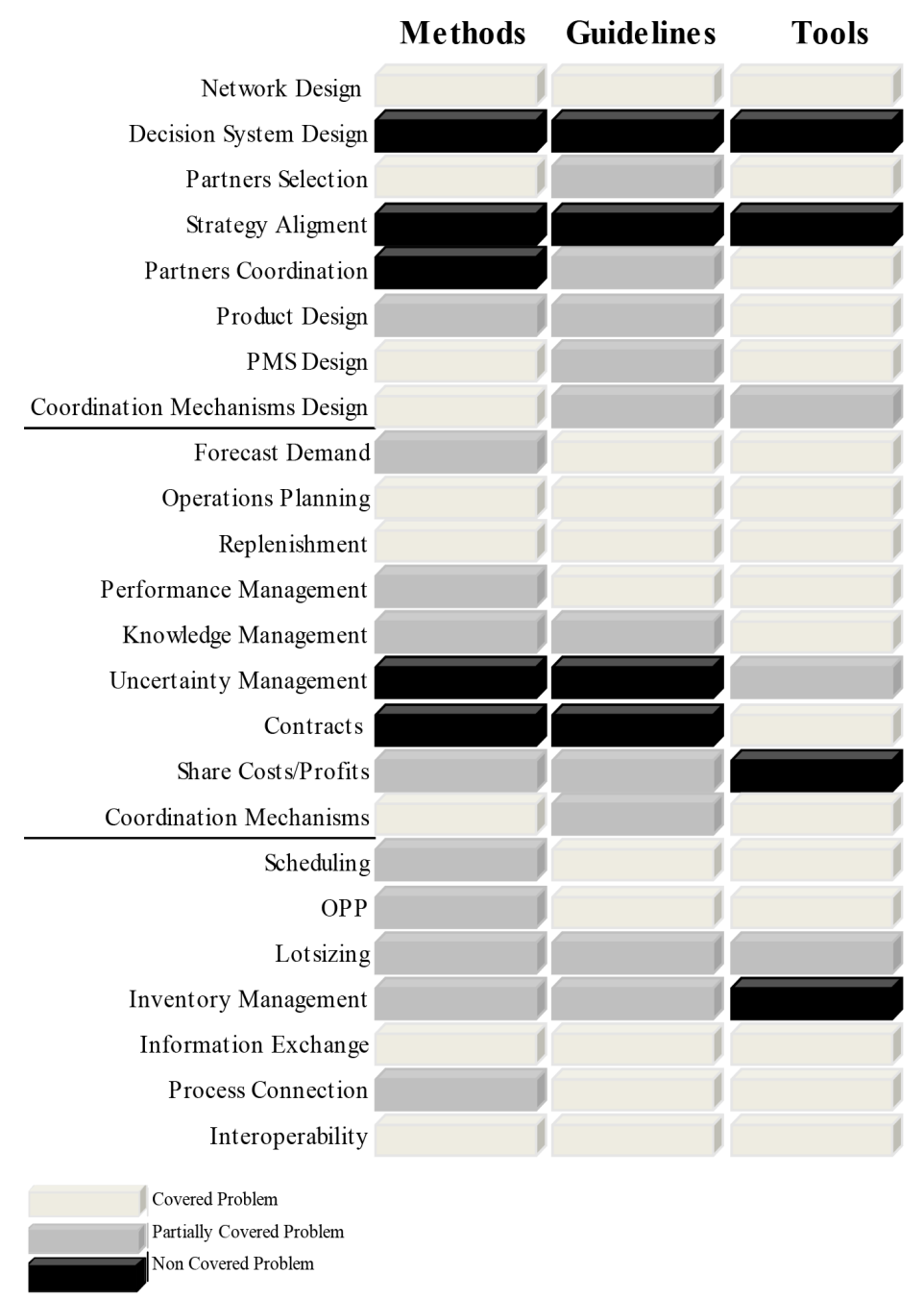

Figure 4. Building blocks for NHN Collaborative Framework. Problems with less satisfactory solutions in NHN context

\section{Conclusions}

There exist many types of problems affecting inter-enterprise collaboration. This paper has proposed a methodology that allows us to identify the most relevant problems, in collaborative networks context, to be solved in the future.

The identification of collaborative problems reveals the existence of many problems affecting inter-enterprise collaboration, most of them treated in HN context. Andrés and Poler (2011) relate both relevant problems and solutions that have been studied in the collaborative context. To each problem is associated the degree of coverage, that is the extent to which the provided solution can be implemented in NHN. The criteria used to identify the relevant problems to study is: (i) the degree of coverage of the solution and (ii) the degree of significance to establish decentralized and collaborative relationships. In this way, through the proposed methodology problems with unsatisfactory degree of coverage solutions and relevant for establishing collaborative relations have been detected. The relevant problems for providing solutions in NHN are (i) at the strategic level: network design, decision system design, 
partners selection, strategy alignment, partners coordination, product design, and coordination mechanisms design (ii) at the tactical level: knowledge management, uncertainty management, contracts, share costs and benefits and coordination mechanisms management and (iii) at the operational level: inventory management, and process connection, interoperability and information exchange problems. The listed problems are identified as important to provide solutions in the NHN context.

The expected contribution of the future dissertation research is to develop a framework (mentioned in section 3 ) for providing models, guidelines and tools for supporting collaborative processes, specifically in the non-hierarchical context. The framework is aimed to achieve a better understanding how SMEs deal with collaborative problems in NHN.

\section{References}

Andrés, B., \& Poler, R. (2011). Análisis de los Procesos Colaborativos en Redes de Empresas No-Jerárquicas. XV Congreso de Ingeniería de Organización. Cartagena.

Poler, R., Ortiz, A., Tormo, G., \& Gutierrez, D. (2002). Practices in Knowledge Management in Small and Medium Firms in Enterprise Inter. And Intra Organizacional Integration Building International Consensus. En L. Camarinha-Matos \& $\mathrm{H}$. Afsarmanesh, Processes and Foundations for Virtual Organizations, 217-224. Kluwer Academic Publishers.

Poler, R. (2010). Intelligent Non-Hierarchical Manufacturing Networks (iNet-IMS). Intelligent Manufacturing Systems. http://www.ims.org/sites/default/files/iNet-IMS\%20MTP\%20Initiative \%202009\%20v1.3.doc

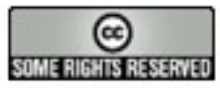

Article's contents are provided on a Attribution-Non Commercial 3.0 Creative commons license. Readers are allowed to copy, distribute and communicate article's contents, provided the author's and Journal of Industrial Engineering and Management's names are included. It must not be used for commercial purposes. To see the complete license contents, please visit http://creativecommons.org/licenses/by-nc/3.0/. 